\title{
An Intelligent Decision Support System Using Adaptive Network- Based Fuzzy Inference System (ANFIS) For Choosing Suitable Bank Loan Installments
}

\author{
Ibrahim Albidewi ${ }^{1}$, Rana Alouhali ${ }^{2}$ \\ ${ }^{1,2}$ (Faculty of computing and Information Technology/ King Abdulaziz University, Saudi Arabia)
}

\begin{abstract}
Choosing the best bank to obtain a loan from has become a dilemma for many loan applicants; Thus the need to automate the process throughout establishing an intelligent decision support system (IDSS) to facilitate applicant's decision-making process. However, there are many types of IDSS to design the system but we have found that the fuzzy logic is more suitable. Despite the fact that Fuzzy structure has strong inference system, it has no learning ability. In the contrary, neural network (NN) has a powerful learning ability. The Adaptive Network-based Fuzzy Inference System (ANFIS) merges these two desired features in its own structure. Therefore, using the ANFIS to determine the best loan package was proven in this paper to define the suitable bank.
\end{abstract}

Keywords: Adaptive Network-based Fuzzy Interface, ANFIS, Decision Support System, Fuzzy logic, neural network.

\section{I.Introduction}

Taking decisions is certainly the most important task of an individual and it is often a very difficult one. Making appropriate decisions requires having information about that specific environment [1]. Decision support systems (DSS) is considered as critical part of a decision maker's toolkit by providing necessary support to facilitate decision making [2].

The process of choosing an appropriate loan package is an important process for loan applicants. Financial services and finance options have become very competitive as well as complicated. An individual interested in obtaining a loan or other financial service has a wide array of options and financial institutions to choose from. Banks and finance companies have different options which satisfy the needs of the customer but also have a list of conditions and commissions associated with the loans. Nowadays, bank loan becomes more complicated than ever. With more than twelve banks in Saudi Arabia providing several types of loans with different conditions and rules makes the choosing process time consuming and troublesome. The need to have computerized information systems that supports decision-making activities in suitable bank loan Installments package is required. The rapid growth of technology has enabled the use of Intelligent Decision Support Systems (IDSS) as a timesaving, error-free alternative to manual selection.

In this paper the authors produce a cooperative decision making by engaging IDSS and Neuro-Fuzzy System. The neural network has an advantage over linear system which is that neural network is more capable to solve problem with hidden connections. The concept of neural network is to create balance between the weights of internal and external neurons through the entire network. Fuzzy logic (FL) is an approach used to solve problems and control systems. FL works even if the information is missing, indefinite, and splitting. FL methodology of dealing with problems is similar to human but faster. Integration of these two makes a hybrid neuro-fuzzy system, based on general facts like of human justifications in relation with hidden connections. Therefore, Implementing hybrid neuro-fuzzy system will has a remarkable impact. ANFIS (Adaptive Network Based Fuzzy Inference System) is a 5-layer feed forward neuro-fuzzy system.

In this paper the authors used the ANFIS to define the suitable bank loan an applicant can obtain, the use of ANFIS was built based on an real data obtain from five major banks in Saudi Arabia, and based on those real data and the banks requirements the system was able to build the rules that led to determine the best bank the applicant can obtain his loan from, based on his financial income, nationality, loan period and employment status. Major decisions has to be made by the borrower based on different variables.

For example, the borrower must decide if he needs a short-term loan or a long-term loan. He also has to take into consideration his ability to pay back the loan which is dependent on the commission and fees charged by the bank. The process to choose a bank for the loan should be individualized to meet the specific needs of the borrower. For the banks, determining which loan applicant should be extended credit, as well as the amount of credit, are major practical decisions that confront commercial bank lending officers and loan committees analysis of quantitative and qualitative information for the applicant's financial health is required to make a 
decision. Managing this information can provide a competitive advantage with the highest payoff coming from a lending expert using the information which produces the best possible results to the customer and the bank [3].

The process of choosing a bank loan Installments is still not automated and it is a time consuming and troublesome to the Loan Applicant. Current systems do not provide this functionality to help the customer on decision-making on suitable Installment loans. Loan Applicant (LA) will have choices on selecting a suitable bank loan Installments package for them. LA who are interested in the loan packages need to contact banks Loan officer or through banks' web pages in order to get information before they can make their decision on choosing appropriate bank loan Installments package which meet their needs.

Saudi Arabian Monetary Agency (SAMA): SAMA is the central bank of the Kingdom of Saudi Arabia, was established in 1952 [4]. The APR (Annual Percentage Rate) calculation is made by SAMA relies on the premises of the credit contract period validity and the fulfillment of both creditor and borrowers obligations. On account of clauses in credit agreements that allow alteration on the borrowing or profit share in the APR calculation that is not determined at the calculation time, the annual percentage share will be calculated as if the borrowing or profit share and other charges are fixed in the relation to starting level and will stay applicable until the end of the agreement. In this case, the borrower would be aware that the calculated APR may vary depending on the borrowing or profit share or any other inevitable costs.

Due to complexity that surrounds commercial banks' crediting processes, Eletter and Yaseen [5] came up with an outline that recognizes false neural networks in loan requests. Neural networks are reliable substitutes to the current prediction and cataloging approach as it is capable of highlighting unrelated and difficult associations. This invention enabled banks in Jordan to employ a 'multi-layer feed-forward' neural systems that uses reverse transmission learning during appraisal of credit applications.

If fuzzy grouping is employed, it is possible to come up with a combined economic knowledge by developing a competition catalogue that utilizes four main parameters [6]. This combination of global economic awareness pointers offer the general information of a specific economy, which influence decisions to be made by local and foreign investors. A four steps procedure can be used to realize the index combination that is, analyzing relationships, analysis of major elements, preparation of an ANFIS structure and lastly creation of a combined catalog from all the existing catalogs. The initial stage investigates the association linking the chosen catalogs and its power. Analysis of major elements is done to assess interconnections of available catalogs and find out if they can be harmonized. Adaptive Neural Fuzzy Inference System was utilized to constitute regulations that curve out a subordinate replica that establish how additional catalogs contribute to the resulting constitution of awareness pointers. An original 'Unified Knowledge competitiveness and Progress Indicator' (UKPI) is developed from the cumulative catalogs making a comprehensive catalog that depicts general speed of competitive awareness and resulting improvements in a given region [6, 7].

Edit J. Kaminsky; Holly Danker-McDermot and Freddie Douglas III [8] have published a chapter appears in the book, Computational Economics: A Perspective from Computational Intelligence discusses artificial computational intelligence methods as applied to cost prediction. They presented the development of a suite of hybrid fuzzy-neural systems for predicting the cost of performing engine tests at NASA's Stennis Space Center testing facilities. The system is composed of several adaptive network-based fuzzy inference systems (ANFIS), with or without neural subsystems. The output produced by each system in the suite is a rough order of magnitude (ROM) cost estimate for performing the engine test. Basic systems predict cost based solely on raw test data, whereas others use preprocessing of these data, such as principal components and locally linear embedding (LLE), before entering the fuzzy engines. Back propagation neural networks and radial basis functions networks (RBFNs) are also used to aid in the cost prediction by merging the costs estimated by several ANFIS into a final cost estimate.

\section{Findings And Research Model Presentation}

Applying Islamic law is resulting from the Islamic injunction against Riba (interest). Islam prohibits interest on loans regardless of their nature or purpose. Riba was categorically prohibited through both Quran and the Sunnah of the Prophet leaving no room for any contrary or reverse opinion [9].

To put up with the provisions and regulations of money lending cooperate businesses to adhere to when granting individuals and family members' loans, Saudi Arabia Monetary Agency popularly known as SAMA has reviewed its Consumer Credit Agreement (CCA) and associated its guarantee agreement in January 12006. The following summary clearly describes CCA: There are possibilities of awarding loans to the applicants as 'a side activity', without reference to his main business. It involves individual loans, credit payments, acquisition of assets to be paid for overtime among others. To fund buying of equipment and services for leisure and many others related necessities. Co-operate housing and land investments and home development financial assistance is part of CCA provisions but loan for buying individual or family house is not part of it. To evaluate the applicant's capability to service the loan, banks may ask the applicant to avail current records of their 
investments, monthly salary and potential assets. The required information in the agreement for awarding and repayment of loans ought to be written or otherwise recorded for purposes of future reference.

The records containing details of buying and selling of supplies should be in line with the provisions of the Bank's Sharia'a Committee in case of transactions related to Islamic Products. The bank has to ensure that grant is provided for the specified function. The applicant should be served with all the documents showing details of the agreement governing the award, applicant's letter of acceptance and reception and scheduling of repayment. The Islamic law offers many barrowing techniques which are currently used in many of the banks in Saudi Arabia which are used as alternatives to interest based financing.

This is a documentation prepared by 'Saudi Credit Bureau (SIMAH)' outlining all the details concerning a customer's borrowing and repayment trends throughout their active loan application period. SIMAH receive it operational license in 2002 and initiated its services to the public in 2004 using the terms and conditions developed by SAMA. It is the only body of its kind providing data and monetary services to customers of associate banks in Saudi Arabia.

The loan process and requirements in the kingdom of Saudi Arabia varies from bank to another due to the different type products offered by the banks. SAMA in its Consumer Credit Agreements (CCA) has outlined the general rules that should adhere to by all banks in Saudi Arabia to design their own products.

There are many methods banks use to calculate the loan profit rate and each method will change the amount of the profit rate customer pays. The loan shall be calculated in accordance with the following mathematical formula [10]:

Present Value Annuity Factor $=[$ i/ $(1-(1+i)-n)]$

Monthly Payment = Loan Amount/ Present Value Annuity Factor

Loan Amount $=$ Monthly Payment * Present Value Annuity Factor

$\mathrm{i}=$ Profit Rate

$\mathrm{n}=$ number of period.

For example if the loan amount SAR 100,000 for 5 years at profit rate $6 \%$ per annum, what is the monthly payment?

- Rate per period $=6 \% / 12=0.50 \%$

- Number of Periods $=5$ (years) $* 12$ (months/ year) $=60$ (months)

- Loan Amount = 100,000 (money received, the loan).

Monthly Payment $=100,000 /[0.005 /(1-(1+0.005)-60)]$

$=1933.28$

If we have the monthly payment and we need the loan amount then:

Loan Amount $=1933.28 *[0.005 /(1-(1+0.005)-60)]$

$=1933.28 * 51.7256$

$=100,000$

\section{III.Fuzzy Logic}

Insufficiency of 'Boolean Algebra' to majority of the issues in the world of reality is the foundation of fuzzy reasoning theory, as initially described by a mathematician by the name Lotfi Zadeh in the year 1965. The world of reality has a lot of inaccurate knowledge; people are capable of identifying and defining these inaccuracies, fuzzy structures comprise of information and procedures that aid individuals and institutions in these process of identifying and analyzing inaccuracies. The most important element of a fuzzy structure is the collection of information and instructions made up of 'if-then' commands. If followed by then commands are declarations whereby a number of terms illustrate constant purpose membership.

Maghsooloo, Khosravi \& Shadkam [11] asserts that fuzzy rational decision structures have the following advantages to individuals and organizations;

a. Fuzzy logic is simple to and easy to understand.

b. The flexibility of fuzzy logic approach. You can easily modify it without starting from scratch.

c. Tolerance of the imprecise data.

d. Fuzzy structures allow combinations with other regular technological configurations,

e. They are capable of simulating irregular tasks of random difficulty,

f. These arrangements create a platform on which individuals and institutions can employ the information and records of others who have interacted with the system, as opposed to neuro arrangements that produce dense, unclear simulations from the instruction information,

g. Fuzzy arrangements are founded on the same interaction patterns as people,

h. These systems can be modified to operate with all available variations of 'input-output' sets of information,

i. Apart from strengthening and reducing complexity of ordinary control procedures, fuzzy structures are capable of substituting them, 
j. Fuzzy software employ ordinary instructions

k. Fuzzy logical arrangements are capable of surpassing the knowledge and understanding of professionals

Fuzzy structures are made up of four elements, they include; rule base, prediction engine, fuzzification and defuzzification. The fuzzification unit changes all imputed information to varying levels of associations through appraisal of other groups of associations. The fuzzification unit therefore compares and appraises the keyed in information against the existing operational guidelines to establish the harmonization of a specific input and the circumstances revolving around it. In this process there is an extent to which each input has consistency with any specific rule of operation. Fuzzy IF-THEN rules are the major component of these structures as all the other components handle and manipulate these rules for higher reliability of the output. The prediction element is responsible for merging the available records of rule with the imputed information to gain results that matches with the predicted guidelines.

Composition oriented prediction and personal rule oriented prediction are the two main ways of predicting using a collection of regulations. The person-oriented predictions use each rule in the fuzzy regulations unit to establish a fuzzy product, grouping of these products make up the final fuzzy results. The grouping may be realized using two major approaches; intersecting or uniting. The composition-oriented prediction brings together all single entities into a major collection of regulations, which is referred to as the 'ifthen rule'. Selecting the most applicable prediction approach in a given situation can be done using one of the following procedures; special features, intuitive appeal and computational efficiency.

According to Lin, Han \& Wang [12], for every input, the fuzzy system gives a prediction, which elaborates the corresponding degree to which that alternative can be applied to solve a given problem. Defuzzification is an ordinary process that converts fuzzy data to become a unit with a given importance in the problem solving process. This operation follows any one of these procedures; 'average weight and maximum average association, Center of Singleton (COS), Center of Gravity (COG), and maximum association'.

Neuro fuzzy structures are mixtures of neural networks and fuzzy structures following an arrangement that gives 'neural network algorithms' a higher ability in establishing the measures that fuzzy structure operate on. Therefore, the ultimate objective of a neuro fuzzy arrangement is to; automatically increase the efficiency of a fuzzy structure through application of neural network procedures. The fact that they are founded on fuzzy structures with unclear communication, neuro arrangements should be explained following the if-then regulations. Fuzzy neuro arrangements employ learning procedures produced by neural processes to establish the operational measures of a fuzzy design. Learning algorithms are generally employed in the process of symbolizing fuzzy arrangements in a unique structural design that resemble the neural processes. Neuro processes are instructed using learning algorithms like 'back propagation'. In order to realize the system, we need to replace the functions used in the fuzzy system (like min and max) by differentiable functions or do not use a gradient-based neural learning algorithm but a better-suited procedure [13].

The regulations of fuzzy structures are often installed into the structure as unclear symbolic illustrations that may be described as blurred examples of instructional information. Neuro systems are not supposed to be viewed as a type of 'fuzzy' proficient network; neither does it stand for blurred logic in any way. It may be seen as a unique type of 'feed forward neural processes'. Elements of these processes utilize tconorms or t-norms and not launching of tasks that are generally applied in neural connections. Fuzzy groups of instructions are programmed as 'fuzzy' associations.

Adaptive Neuro Fuzzy Inference System (ANFIS) is created out of Fuzzy Inference System (FIS) of sugeno kind in order to increase the ability to interpret information. The improvement can be described as uncomplicated information sharing expertise through redesigning neuro fuzzy design with a more productive mixture of learning regulation. Fuzzy predictive systems analyze imputed information by plotting it against the available alternatives to generate objective feedback. Adaptive neuro fuzzy inference system has the following merits :

a. It does not rely on previous technical know of people,

b. ANFIS offer more alternatives of association functions to capitalize on,

c. Utilize association tasks in addition to preferred information to estimate the most practical alternatives,

d. ANFIS has high speed of harmonizing imputed data and presenting feedback,

e. To interpret and explain the performance of complicated system ANFIS improve

According to Power [14], ANFIS describes several levels of tasks that work together to execute fuzzification of imputed data;' analysis of foundations, analysis of task output standards, calculating total associations and standardization of calculated total associations.

Majority of ANFIS systems are made up of the following sequential interpretational levels; 
The input level which handle keyed in information that is potted onto the association task pane for establishment of magnitude of association each set of data makes up the initial level of the system, this procedure may be described using the following equations;

$$
\mathrm{Xi}(\mathrm{x})=\mathrm{i}=1,2 \quad \mathrm{Yi}(\mathrm{y})=\mathrm{i}=1,2
$$

Where, $\mathrm{Xi}$ and $\mathrm{Y}$ represent the fuzzied characters that have been imputed, ai, bi and ci are the are the group of measures emanating from the Gaussian input association tasks. Level two of the neurons stand in for the relationship existing between input and output using the fuzzy regulations. Use of the resultant outcome (AND) to the blurred fed in data constitutes the execution of fuzzy task implementers which can be illustrated using the following equation;

$$
\text { 'R1 = X1(x) +Y1 (y), R2 = X2 (x) +Y2 (y), R3 = X3 (x) +Y3 (y), R4 = X4 (x) + Y4 (y)'. }
$$

The products are standardized and consequently conveyed to the next level. Standardization and establishment of the extent of association is carried out following the this equation;'

$$
\mathrm{Gi}=\mathrm{Ri} /(\mathrm{R} 1+\mathrm{R} 2+\mathrm{R} 3+\mathrm{R} 4)^{\prime} \text {. }
$$

From level three above the produced information is plotted on the forth level to generate association tasks using the prearranged fuzzy regulations. The resiliency and practicability of each product item produced is calculated using the this equation;

$$
\text { 'Oi }=\mathrm{Gi}(\text { pix }+ \text { qiy }+ \text { ri }) \mathrm{i}=1,2,3,4 \text { '. }
$$

This equation represents the outcome standardization launching estimates and single entity's product association functions, pi, qi and ri are the measures of operation generated out of the product association tasks. The products are added up in the fifth level to issue forth a product with only one value.

According to Piero \& Goebel [15], ANFIS systems is limited by the fact that it can merely be illustrated as a solitary product structure and can only be made of harmonious weights for every single regulation.

\section{IV.Implementation and Result}

The methodology used for this research was:

- 150 actual samples were collected from five Banks in KSA (testing data).

- ANFIS was used to design the prototype.

- MatLab language was used to write the program.

- Microsoft Office Excel was used to generate the learning data and analyze the results.

150 real symbols were collected from five different banks as follows :

- The Saudi British Bank

- The National Commercial Bank

- Samba Financial Group (Samba)

- Bank AlJazira

- Bank AlBilad

Each bank provided us with 30 randomly selected loans that have been granted. The symbols were collected totally randomly to ensure a wider range of likelihood as follows .

1. To designate the boundaries for the training data, we used the highest and lowest Monthly Salary and Loan Period in the real symbol

2. Generated 10,000 random values for the Monthly Salary and Loan Period using Microsoft Excel function RANDBETWEEN(Bottom; Top).

3. Generated 10,000 random values for (Saudi or non-Saudi) and (Government or nongovernment employer) using Microsoft Excel function RANDBETWEEN $(0 ; 1)$.

4. Each bank in KSA has a fixed profit rate. However, there are six rules that the banks in KSA use to calculate the profit for a loan. The rules can either increase or decrease the profit rate. The rules are:

- Fixed

- $\quad$ Loan period from 60-120 Months $=$ Rate $+0.5 \%$

- $\quad$ Loan more than 120 Months = Rate $+0.75 \%$

- Major Government Companies ( Saudi Airlines, Aramco, Sabic, STC, SEC) = Rate $0.5 \%$

- $\quad$ Non- Saudi $=$ Rate $+0.75 \%$

- Monthly Income more than SAR 25,000 = Rate- $0.75 \%$

Nevertheless, not all the banks apply the six rules.

5. The best loan provider was determined on the basis of profit rate. After calculating the accumulated profit rate for each bank, we chose the lowest profit rate using the function Min () for each generated random value. 
From the above comparison we found that the result of both 10,000 and 1,000 training data are the same. Except that the processing time was longer in the 10,000 training data, thus we used the 1,000 training data.

ANFIS can be accessed either from the m-file programs or through the ANFIS Editor GUI, since both have a similar functionality. M-file was used to write the code and then ANFIS Editor GUI was used to develop the graphs.

To work with m-files, all files need to be included in the MATLAB working path. The functions used to write the m-file are :

- "XLSREAD" gets the training data from a spreadsheet in an Excel workbook.

- "GENFIS1" Generates an initial Sugeno-type FIS for ANFIS training.

- "ANFIS" Adaptive Neuro-Fuzzy training of Sugeno-type FIS.

- The training process stops whenever the designated epoch number is reached.

- "EVALFIS" Perform fuzzy inference calculations as in the following form: Y = EVALFIS (U, FIS) simulates the Fuzzy Inference System "FIS" for the input data "U" and returns the output data "Y".

- "FIGURE" creates figure graphics objects.

- "SUBPLOT" create axes in tiled positions.

- "PLOTMF" display all of the membership functions for a given variable.

- "SIZE" returns size of array .

- "ROUND" round towards nearest integer.

To start the ANFIS Editor GUI, the command "anfisedit" needs to be typed in the command window. The FIS Editor present the title of every single input and product changeable factors. The membership functions appearing in the cube like structures are just visual representations and actual shapes of the association tasks. The Membership Function Editor is a tool that displays and edits the membership functions related to the input and product changeable factors of the fuzzy system.

Rule viewer allows the individual to interpret the whole system at once, show how each association impact on the entire process and calculations.

The surface viewer presents and illustrates associations on a chart; the product against a few inputs on. This is shown in the following Figures.

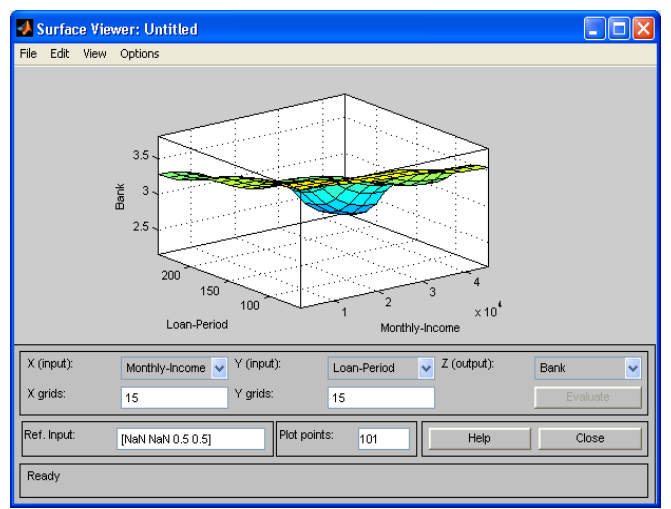

Fig 1. Surface chart for Monthly Income \& Loan Period Vs. Bank number.

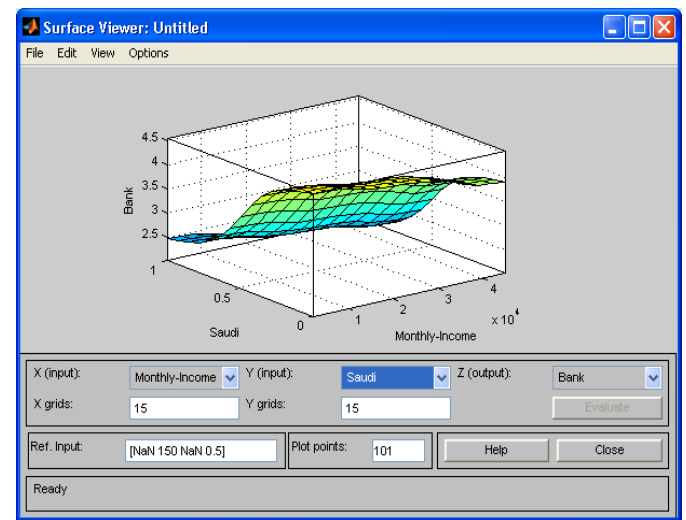

Fig 2. Surface chart for Monthly Income \& (Saudi or Non-Saudi) Vs. Bank number. 


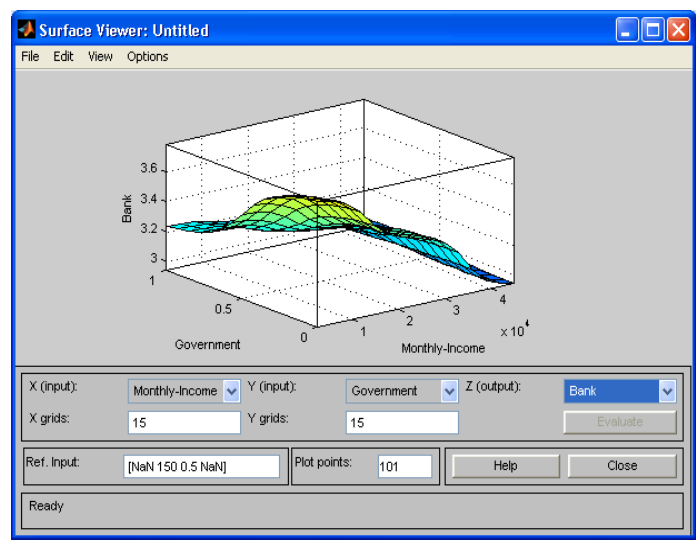

Fig 3. Surface chart for Monthly Income \& (Government or Non-Government employed) Vs. Bank number.

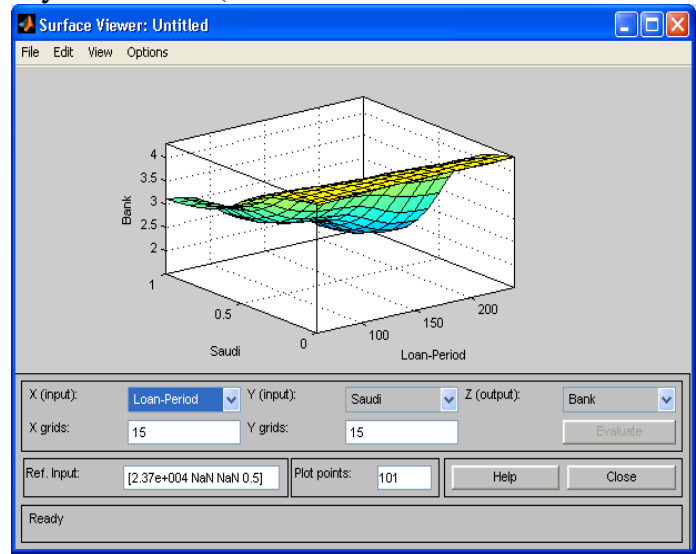

Fig 4. Surface chart for (Saudi or Non-Saudi) \& Loan Period Vs. Bank number.

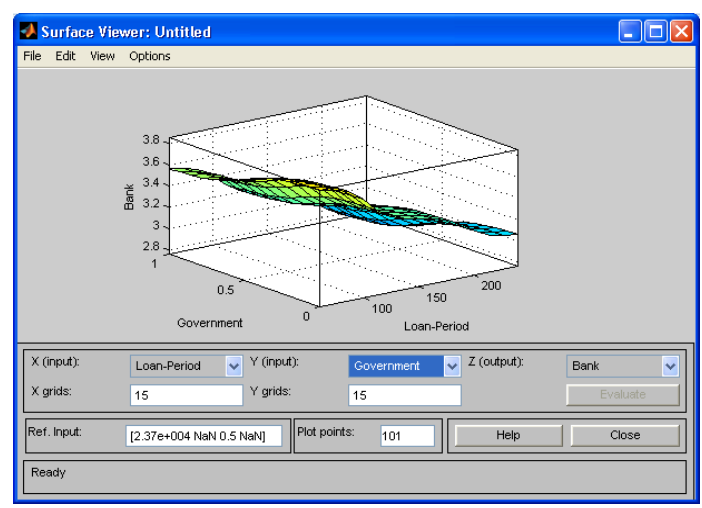

Fig 5. Surface chart for (Government or Non-Government employed) \& Loan Period Vs. Bank number.

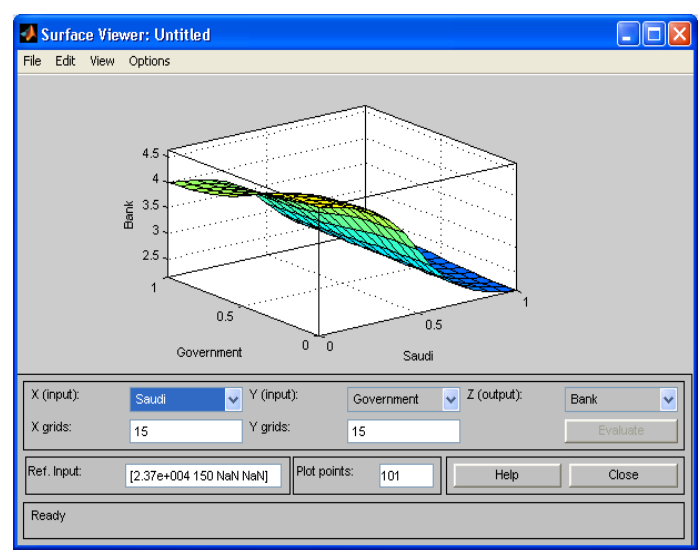


Fig 6. Surface chart for (Saudi or Non-Saudi) \& (Government or Non-Government employed) Vs. Bank number.

The data set used in this research consists of training data (1,000 subjects) and testing data (150 subjects). After training the system, we tested the real data that the banks provided us to find whether the borrowers had made the right decision or not. The 150 real symbols consist of 30 symbols collected equally from each bank. However, after testing the symbols, ANFIS suggested a different distribution of the symbols.

When we trained the system with the 10,000 generated symbols, it took the system 27 minutes to compile and produce the output. However, when we trained it with 1,000 symbols it produced the same results, yet it only took 2 minutes to compile and return the results. Therefore, we decided to use 1,000 symbols instead of 10,000 .

\section{V.Conclusion And Future Work}

This paper illustrates that each bank has his own requirements to grant a loan for individuals, such requirements varies between each bank and the parameters used are not the same since each factor has its impact on the bank profit rate; thus the need to use an intelligent system to assist the applicant to determine the suitable bank is required. Such intelligent system must be able to have both strong inference system and learning ability. ANFIS is a very good system to extract numerical models from numerical data. And it does not require prior human expertise. Consequently, this system is capable of solving the current problems associated with choosing suitable bank loan Installments package.

We have used ANFIS to evaluate the real samples obtained from five different bank is Saudi Arabia, and to find out if the applicant has chosen the right bank; we have generated 10,000 random sample data with different possible scenarios to define the best bank for each sample on the basis of lowest profit rate. Hence, we was able to generate ideal sample and use them to train the system. After the system has been trained, we tested the real samples and found that $76 \%$ of the borrowers chose the wrong bank. Such results show how empirical it is to use the ANFIS to suitable bank loan an applicant can use.

\section{References}

[1]. Park, Yong-tae, An empirical investigation of the effects of data warehousing on decision performance, Information \& Management Journal 2005, 51-61.

[2]. G. M. Marakas, Decision Support Systems in the 21st century, 2nd Edition (New Jersey: Prentice Hall, 2002).

[3]. Shaw, J. Michael, and A. James, Gentry, Using an Expert System with Inductive Learning to Evaluate Business Loans, Financial Management, 1988, 45-56.

[4]. SAMA, About SAMA, 2010. Last access January 2014, Retrieved from: http://www.sama.gov.sa/sites/samaen/aboutus.aspx.

[5]. Eletter, S. Fathi, \& S. G. Yaseen, Applying Neural Networks for Loan Decisions in the Jordanian Commercial Banking System, International Journal of Computer Science and Network Security, 10, 2010, 209-214.

[6]. A. A. Shami, A. Lotfi, E. Lai, \& S. Coleman, Unified Knowledge Economy Competitiveness Index Using Fuzzy Clustering Model, IEEE Symposium on Computational Intelligence for Financial Engineering and Economics (CIFEr), 2011, 1-6, IEEE.

[7]. Hui, Zhao \& W. Xue-qing, Study on Real Estate Project Investment Decision-Making Based on Principal Component Analysis and Adaptive Network-Based Fuzzy Inference System, International Conference on Biomedical Engineering and Computer Science (ICEBECS), Wuhan, ICEBECS, 2010, 1-4.

[8]. Edit J. Kaminsky, H. Danker-McDermot and F. Douglas III, Economics: A Perspective from Computational Intelligence, edited by Shu-Heng Chen, Lakhmi Jain \& Chung-Ching Tai ( Idea Group Inc., 2006)

[9]. Ahmad, Ausaf, Contemporary Practices of Islamic Financing, Research Paper, Islamic Development Bank, Riyadh, 1993.

[10]. Brigham, F. Eugene \& F. Joel, Houston. Fundamental of Financial Management, (New York: Cengage Learning, 2009).

[11]. Maghsooloo, Alireza, A. Khosravi \& A. H. Shadkam, ANFIS and PCA Capability Assessment for Fault Detection in Unknown Non-Linear Systems, ISCCSP 2008, Malta, 2008, 24-32.

[12]. Lin, Bihua, et al., Control of Boiler-Turbine Unit Based on Adaptive Neuro-Fuzzy Inference System, IEEE International Conference on Systems, Man and Cybernetics, Hong Kong, 2003, 2821-2826.

[13]. J. S. R. Jang, ANFIS: Adaptive-network-based fuzzy inference system, IEEE Transaction on Systems, Man and Cybernetics, 1993, 665-685.

[14]. D. J. Power, Supporting Business Decision-Making, (New York: Prentice Hall, 2000).

[15]. Piero, P. Bonissone \& K. Goebel. When will it break? A Hybrid Soft Computing Model to Predict Time-to-break Margins in Paper Machines, Proceedings of 47th Annual Meeting of International Symposium on Optical Science and Technology, Singapore, 2002, 53-64. 